\title{
STUDENT PERCEPTIONS ON THE IMPACT OF MOBILE TECHNOLOGY IN THE CLASSROOM
}

\author{
Dr. Harry Benham Ph.D., Montana State University hbenham@montana.edu \\ Gerard Carvalho, Montana State University jcarvalho@montana.edu \\ Michelle Cassens, Montana State University michellecassens@gmail.com
}

\begin{abstract}
This paper describes student impressions of how using mobile computing devices in the classroom would likely impact their learning. The data came from a survey of student opinions regarding the possible implementation of a Bring Your own Device (BYOD) policy in a college of business. We have been able to demonstrate that students already own the necessary devices required to make a BYOD policy successful. The reasons that students do not currently bring these devices to class do not pose a significant obstacle to the adoption of a BYOD policy. Students already understand the benefits of using mobile technology in the classroom and want to use it more in the future. Finally we are able to create a definite link between Student Wants and Academic Preparation, with the Benefits of using mobile technology in the classroom as well as demonstrate a relationship between Improved Benefits and the Engagement Level of students. Thus BYOD should lead to a more engaged student. The most significant hindrance to making BYOD a success is the student's perception of the current attitude and technical competence of the faculty.
\end{abstract}

Keywords: BYOD, Mobile Devices, Learning, Engagement.

\section{INTRODUCTION}

Today's typical College student is a child of the digital age. Mobile computing has been feasible throughout these students' educational careers. Yet Colleges and Universities seem to have been much more willing to enable on-line courses than to embrace the use of mobile devices in otherwise traditional classrooms and courses. This paper examines students' perceptions of how integration of mobile computing devices into their classroom experience would impact their learning.

There are a number of practical and logistical difficulties with having the instructor provide computing devices for in class usage. There are the costs of purchasing and maintain devices, the loss incurred when devices are not returned or damaged, and loss of valuable instructional time as devices are distributed and retrieved. Despite significant improvements in ease-of-use over the years, it is extremely likely that some instructional time would need to be devoted to learning how to properly use the devices. For these reasons, Bring Your Own Device (BYOD) was the focus of inquiry as the only potentially feasible means to implement mobile device usage in classroom.

BYOD is not a panacea; it comes with its own set of potential problems. When instructors require a device of every student, there is the potential that BYOD simply shifts the financial burden to students. While hopefully each student would be familiar with their own device, faculty would have to adapt to the capabilities of a multitude of devices. There must be sufficient bandwidth for all students to connect all their devices during class. All students must have access to required software. And there is the ever present fear that student might share course information with others outside the classroom. The analysis underlying this paper seeks to discover whether or not a BYOD policy would be feasible or desirable. If it were not feasible, then there would be little point to discovering solutions to BYOD's problems.

This paper is organized as follows: First the Literature Review section will briefly survey what is known about BYOD in an educational context and the impacts of classroom use of mobile computing devices. Following the Literature Review, we look at specific Research Questions. The Data and Methods section reviews how the data was collected, what was measured, and how the data was analyzed. Next, the Data Analysis results are presented and related to the Research Questions. The final section provides Discussion and Conclusions. 


\section{LITERATURE REVIEW}

The literature on the explosive growth of the use of personal mobile devices, also called Bring Your Own Device (BYOD), in both education and business is plentiful and consistent. Thus, it will not be discussed here.

Many of the disadvantages of BYOD involve the loss of sensitive data and an overall loss of control by IT departments [6]. These concerns are mitigated somewhat in an educational setting since each student only has access to their own personal data.

The definition of what constitutes the use of mobile devises for educational purposes is not consistent in the literature. For the purposes of this research we have adopted the definition by Rossing, Miller, Cecil and Stamper: "Mobile learning is the efficient and effective use of wireless and digital devices and technologies to enhance learners' individual outcomes during participation in learning activities" [7].

Much of the research into the use of mobile devices in education focuses solely on the use of tablets, specifically the iPad. This research shows a positive correlation between the use of technology in the classroom, student engagement, and the students' quality of learning [5] [8] [1] [7]. We are extending the list of allowed mobile devices to include laptop computers, tablets, and smart phones since all of these devices can be used in different ways to enhance the classroom-learning environment.

Early research into the use of mobile devices such as iClickers show that students feel more engaged in the classroom when using these devices. IClickers have been shown to increase student participation and engagement in the classroom through the use of interactive teaching techniques. It is apparent that students who are engaged in the classroom above and beyond traditional teaching styles such as lecturing perceive that they experience greater depth of understanding of subject matter [4].

There is a difference in outcomes when people use their own devices instead of organizationally mandated devices. According to Pillay, Nham, Tan, Diaki, Senanayake, and Deshpande, when people use their own devices, devices that they have chosen and invested in, they tend to be happier and more productive [1]. Increased productivity comes from two sources. First, individuals tend to upgrade their personal equipment faster than their organization, leading to an overall improvement in the quality of the devices used. Second, since employees have invested money into these technologies, they tend to also invest the time required to learn the efficient use of that technology.

\section{RESEARCH QUESTIONS AND HYPOTHESES}

Our research questions are fundamentally simple: Do students own appropriate mobile devices they could and would bring to class? How would they anticipate using their devices in class? And how do they perceive that the use of their mobile devices in-class would enhance their educational experience?

\section{Feasibility}

Would a BYOD policy even be feasible? From an organizational perspective, it would be difficult to add to the heavy financial burden on students by requiring them to also purchase a mobile computing device for in-class use. However, if students already own such devices, then asking them to bring the devices to class would not be oppressive. Thus, the first research question is to determine the number of students who currently own various computing devices. And for those students who do own mobile devices, what are the impediments to using their devices in the classroom? More formally:

\section{R1a: What types of mobile computing devices are currently owned by students?}

\section{R1b: If they already own the devices why don't students bring them to class?}

\section{Uses}

How would students anticipate using their mobile computing devices in a classroom setting? Instructors who have experienced inappropriate classroom use of mobile devices may tend to answer that students might text their friends, 
play games, or "surf the Web." While these activities may occur, we believe that most students are interested in furthering their education and doing well in their classes. Thus, our second research question is:

\section{R2: How would students anticipate using a mobile device in class?}

\section{Impact on Learning}

Our presumption is that students' desire to use mobile devices in class stems from their desire to learn the material and develop improved problem solving and problem research skills. Borrowing from the reported increased student engagement by those who have employed iClicker technologies in the classroom, we posit that in-class use of mobile devices would similarly engage students. They would be able to access reference materials, look up facts, or submit questions to be answered before the next class. More engaged students tend to learn more and perform better on exams. Student characteristics, the strength of their desire to use mobile devices in-class, benefits derived from the use of mobile devices in-class, and instructor's attitudes towards technology use in the classroom are posited to influence student engagement. Stated as a null hypothesis,

H1: Student engagement in class is unrelated to the perceived benefits of, student desire to use, academic preparation afforded by, or instructor attitudes toward the use of mobile devices.

This hypothesis is rather all encompassing. Failure to reject the null hypothesis would suggest that in-class use of mobile devices would have no beneficial impact. Assuming that $\mathrm{H} 1$ can be rejected, it would be useful to have a better understanding of the mechanisms by which in-class use of mobile devices effect student engagement.

We suggest that student perception of instructor attitudes and benefits from in-class use of mobile devices are responsible for student engagement. Stated as a null hypothesis:

H2: Student engagement is unrelated to perceived benefits of in class use of mobile devices and student perception of instructor attitudes toward such use.

Student perceptions of the benefits of in-class use of mobile devices in turn, are posited to depend on the academic preparation afforded by use of such devices, student perception of instructor attitudes, and the students' desire to use mobile devices in class. As a null hypothesis:

H3: Perceived benefits of using mobile devices in class are unrelated to academic preparation, student perception of instructor attitudes, and the students' desire to use mobile devices in class.

Finally, students' desire to use mobile devices in class is related to demographics such as age, gender, year in school, and the number of mobile devices they have. In terms of a null hypothesis:

H4: Students' desire to use mobile devices in class is unrelated to their age, year in school, gender, or the number of mobile devices they own.

Figure 1 shows a visual representation of these four hypotheses. To answer these research questions, data was collected and measures constructed as outlined in the following section.

\section{DATA \& METHODS}

As part of a class assignment, a survey was designed and administered to randomly selected students in the Business College. A copy of the questionnaire may be obtained from the authors upon request. Useable data was obtained from a sample of 451 respondents. The available demographic questions indicate that the sample was reasonably representative of the college's student population. Each business major was represented in proportions mirroring enrollment in the majors. Freshman through Master's level students responded and the sample was approximately $40 \%$ female again mirroring the college's student population. 


\section{Issues in Information Systems \\ Volume 15, Issue $x$, pp., 2014}

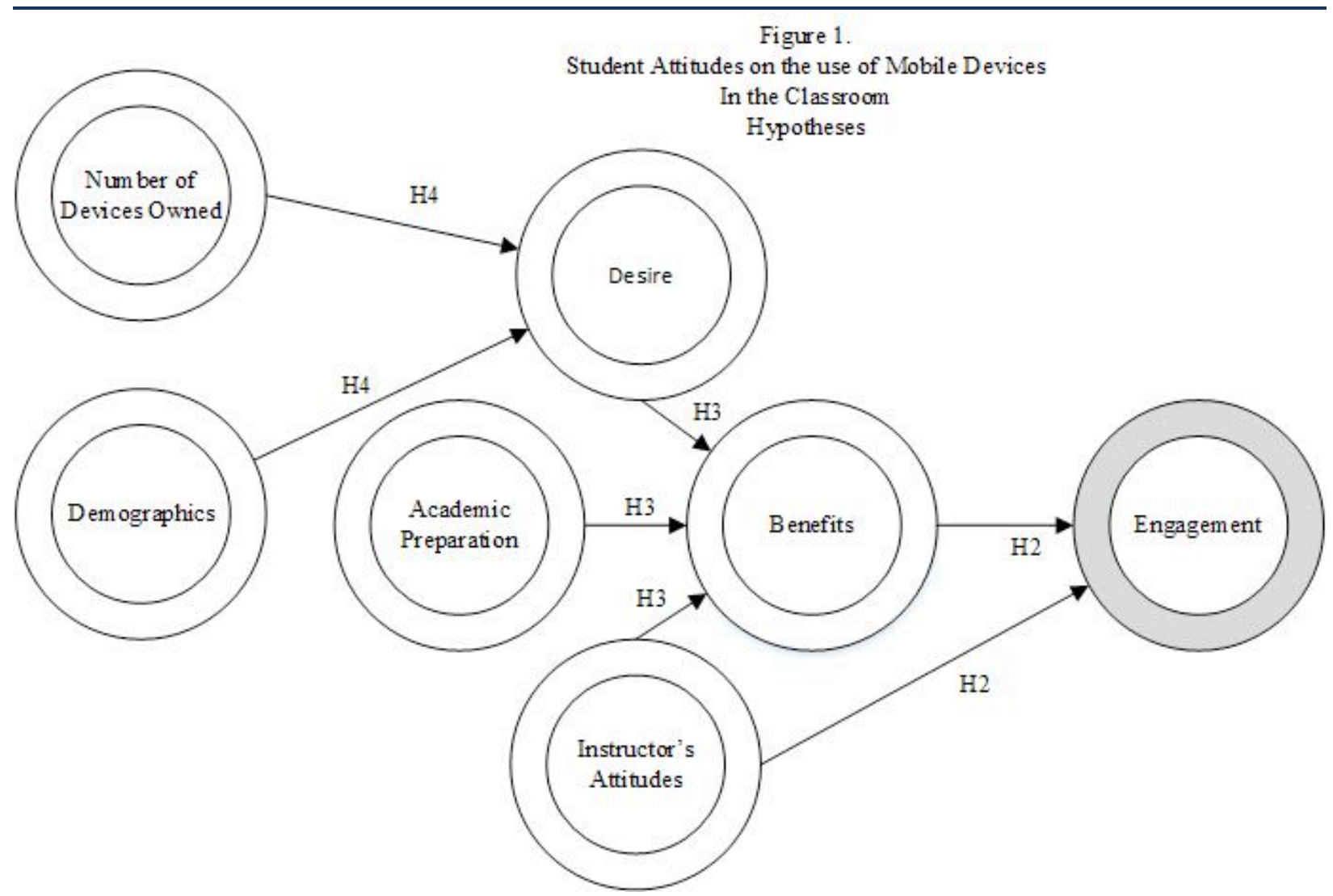

Research Questions 1 \& 2

After the demographics, the next few questions in the survey were designed to provide data to answer the two research questions. Summary statistics and frequency charts of student responses to these questions are an appropriate methodology for addressing the research. The results are shown below in the Results section.

\section{Measurement}

The remainder of the survey consisted of over 20 statements with responses on a 5-point scale from Strongly Disagree to Strongly Agree. Multiple statements were used to elicit student opinions about each of the constructs expressed in the hypotheses.

Factor Analysis was used to obtain a measure for each construct. Not every statement was clearly identified as contributing to a construct measure as we would have liked. But overall, the factor analysis results were good. The statement "My instructors encourage the use of technology in the classroom" loaded very heavily on instructor attitudes. The statement "Technology helps me achieve my academic goals" loaded very heavily on the factor used to measure benefits of in class use of mobile devices. The resulting constructs include: students desire to use technology in the classroom (Desire), the preparation for future academic endeavors that the use of technology in the classroom provides (Academic Preparation), students' perception of instructor's attitudes towards the use of technology (Instructors), the benefits that accrue to the students through the use of technology, excluding Academic Preparation, (Benefits), and finally the level of student engagement (Engagement). The reader interested in additional specifics of the factor loadings may contact the authors for complete details.

\section{Hypothesis Tests}

Linear regression using the construct measures was the technique used to test all hypotheses. For H1, the variable "NumMobileDev" for the number of mobile devices owned by the respondent was also used as an explanatory variable. And similarly, respondent demographic measures and the number of mobile devices were used to explain a respondent's desire to use mobile devices in class. 
A structural equations or a partial least squares approach could have been used to test $\mathrm{H} 2-\mathrm{H} 4$. Such an approach may yet be applied as the standard linear regression results reported below suggest that mechanisms implicit in $\mathrm{H} 2$ $\mathrm{H} 4$ appear to have some validity.

\section{RESULTS}

This section reports our empirical results. The first section addresses research questions R1 and R2. The second section looks at the hypothesis test results for $\mathrm{H} 1-\mathrm{H} 4$.

\section{Research Questions 1 \& 2}

R1a: What types of computing devices are currently owned by students?

FIGURE 2.

Types of Devices Owned By Students

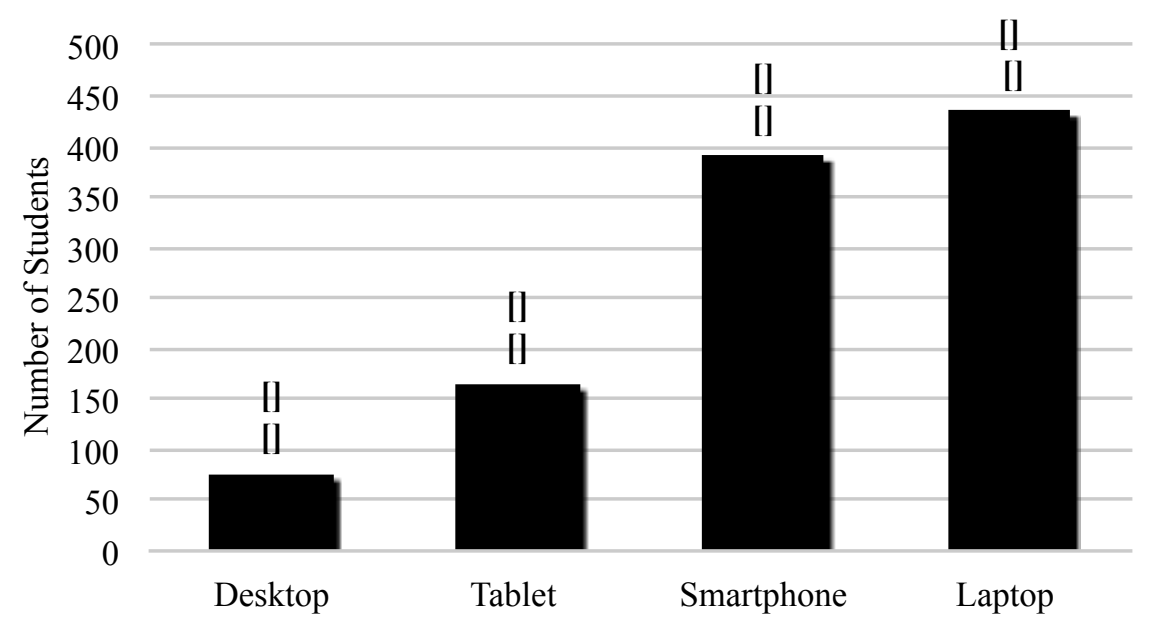

FIGURE 3.

Number of Devices Owned Per Student

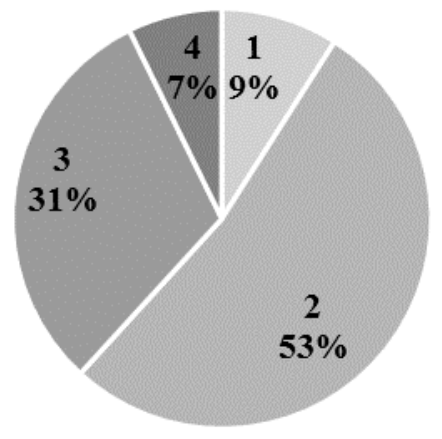

FIGURE 4.

Intended Future Purchases

(Within 12 Months)

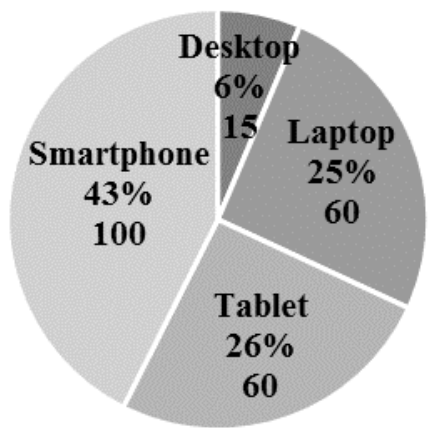

Note that every student already owns at least one mobile computing device, there are no students who do not already own a mobile computing device, and on average each student owns 2.35 mobile devices. Laptop computers and smartphones are the most popular devices. While a little over $1 / 3$ of the students own Tablets and very few students own desktop computers, students' plans for future purchases indicate a preference for smaller, lighter devices. Desktop computer ownership was included in the survey to ensure that no student relied solely on fixed computing technology at the expense of mobile technology. 
R1b: Why don't they bring them to class?

FIGURE 5.

Reasons Not to Bring Laptop to Class

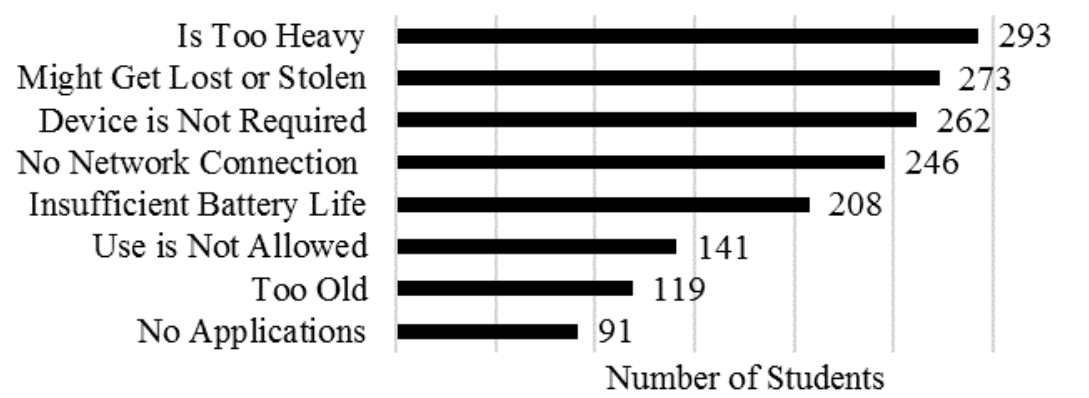

FIGURE 6.

Reasons Not to Bring Tablet to Class

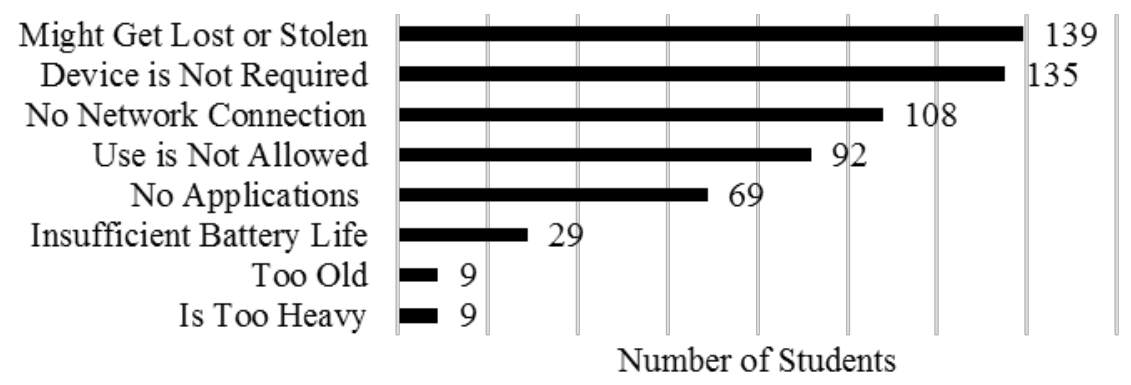

FIGURE 7.

Reasons Not to Bring Smartphone to Class

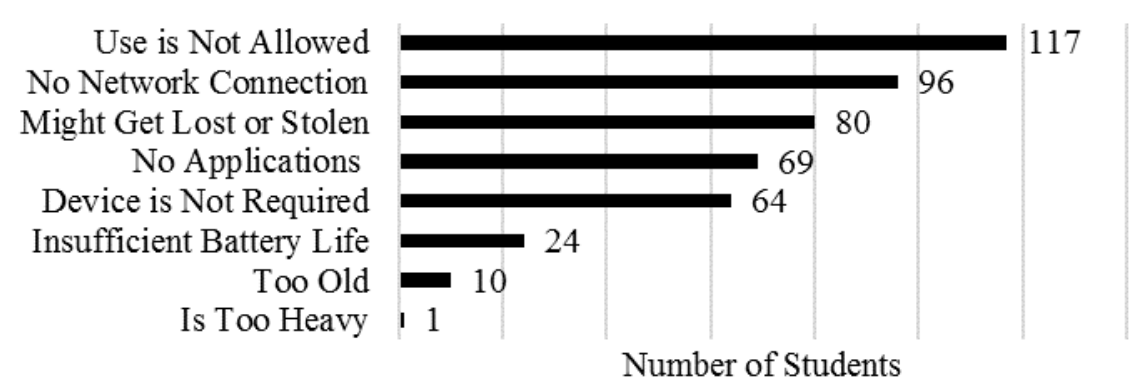

To determine why students, who already own mobile computing devices, do not bring them to class, we broke the data down and looked at laptops, tablets and smartphones separately (Figures 5, 6, 7). The results are remarkably consistent across devices. Fear of loss or theft, the fact that the devices are either not allowed or not required, the inability to get a wireless network connection, and a lack of appropriate software applications for a business curriculum appear repeatedly. Two reasons for not bringing the devices to class, not required and not allowed automatically disappear once a formal BYOD policy is in place. The remaining issues can be dealt with using careful planning and coordination when constructing the policy. 
R2: How would students anticipate using a mobile device in class?

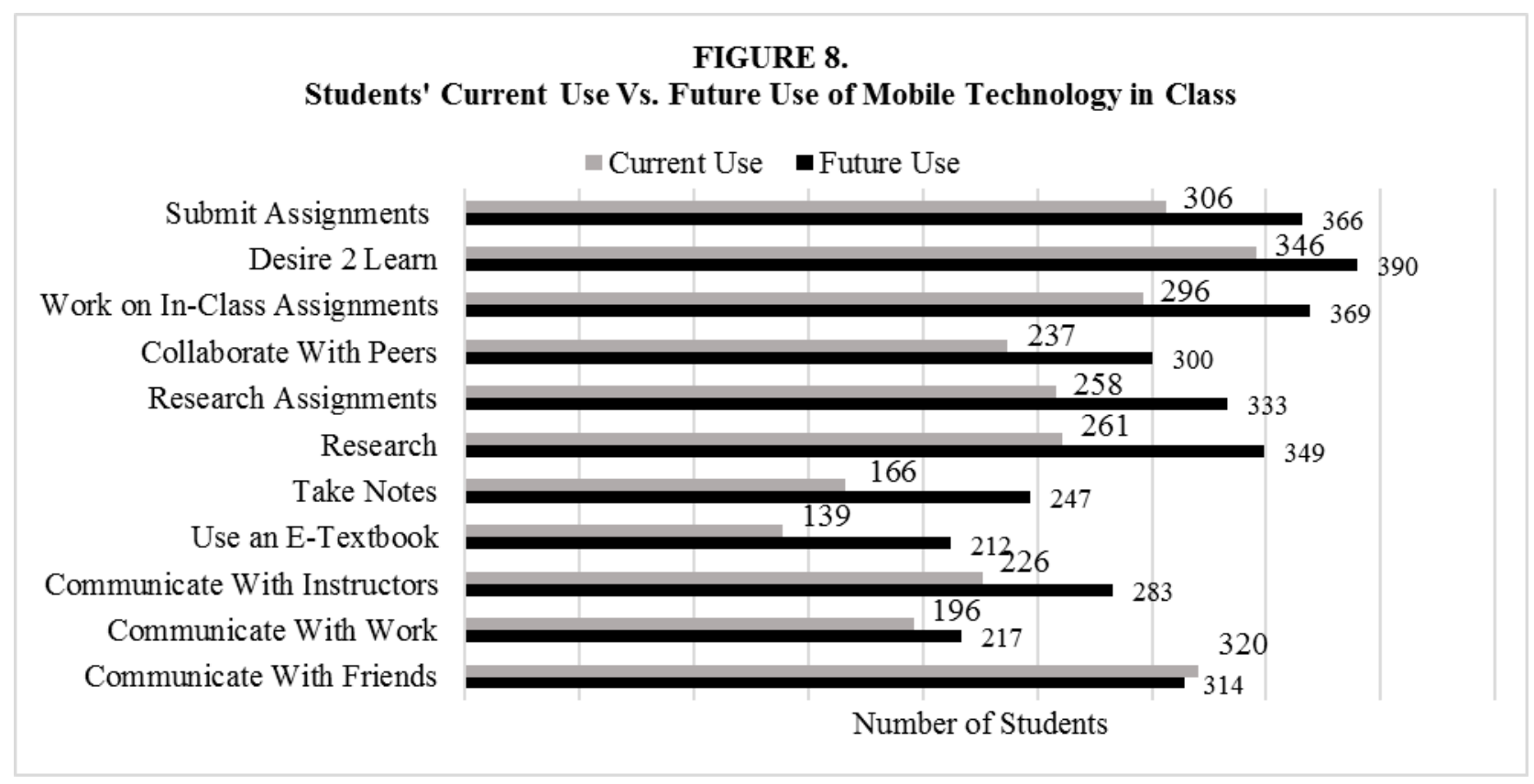

Figure 8. shows that students already understand how mobile devices can be effectively used in the classroom (gray bar) and at the same time, want to do more of those things in the future (black bar). Interestingly, students believe that they will use these devices to communicate with their friends less in the future than they do now indicating an understanding of the important academic uses for these devices while at the same time, downplaying non-academic uses.

\section{Hypothesis Tests}

Table 1 below contains the results of the regression to test H1. The results indicate that students who perceive more benefits from the in-class use of mobile devices and students with a higher desire to use mobile devices in class report greater class engagement. Strangely, students who perceive that they are better prepared academically are less engaged in their class. Stranger still is the unexpected and significant negative effect of students' perception of instructor attitude on engagement. We would have expected that an instructor who encourages the use of mobile devices would be positively associated with student engagement.

TABLE 1.

\begin{tabular}{|l|c|c|}
\hline \multicolumn{3}{|l|}{ Engagement } \\
\hline Variable & Coefficient & t-Stat \\
\hline Intercept & -0.200 & -1.676 \\
\hline Benefits & 0.525 & $11.142^{* *}$ \\
\hline AcademicPrep & -0.147 & $-4.234^{* *}$ \\
\hline Desire to Use & 0.160 & $3.421^{* *}$ \\
\hline Instructor & -0.092 & $-2.556^{*}$ \\
\hline NumMobileDev & 0.090 & 1.721 \\
\hline Adj. $\mathrm{R}^{2}$-Square & .471 & \\
\hline $\mathrm{N}$ & 541 & \\
\hline & * significant at 5\% level, ${ }^{* *}$ Significant at $1 \%$ level \\
\end{tabular}




\section{Issues in Information Systems \\ Volume 15, Issue $x$, pp., 2014}

Table 2, begins to break down the mechanism for how the various explanatory variables in Table 1 exert their influence. Clearly students who perceive greater benefits to in-class use of mobile devices are more highly engaged in their class. The instructor attitude measure is again negatively associated with engagement in class but is not statistically significant at a $5 \%$ level.

TABLE 2.

\begin{tabular}{|l|c|c|}
\hline \multicolumn{3}{|l|}{ Engagement } \\
\hline Variable & Coefficient & t-Stat \\
\hline Intercept & -0.002 & -0.063 \\
\hline Benefits & 0.645 & $17.930^{* *}$ \\
\hline Instructor & -0.063 & -1.745 \\
\hline Adj. R $^{2}$-Square & .432 & \\
\hline $\mathrm{N}$ & 541 & \\
\hline ** Significant at 1\% level &
\end{tabular}

Table 3 continues to break down the mechanism by looking at the influences behind students' perceptions of the benefits of in-class use of mobile devices. Quite clearly, students with a greater desire to use their mobile devices inclass perceive greater benefits from that use. Once again, the instructor variable has a statistically significant negative impact.

TABLE 3.

\begin{tabular}{|l|c|c|}
\hline \multicolumn{3}{|l|}{ Benefits } \\
\hline Variable & Coefficient & t-Stat \\
\hline Intercept & -0.000 & -0.008 \\
\hline Desire to Use & 0.667 & $19.422^{* *}$ \\
\hline Instructor & -0.170 & $-4.938^{* *}$ \\
\hline Adj. R $^{2}$-Square & .469 & \\
\hline $\mathrm{N}$ & 541 & \\
\hline ** Significant at 1\% level &
\end{tabular}

Table 4 completes the breakdown of the mechanism behind the results in Table 1 and tests hypothesis H4. The first thing to note about Table 4's reported results is that only about $4 \%$ of the variance in the Desire to Use mobile devices in class measure is explained. The strongest predictor of a desire to use devices is the number of devices owned. The statistically significant coefficient on gender indicates that males have a higher desire to use mobile devices in class than females. Neither the respondent's age nor their year in school had a significant impact.

TABLE 4.

\begin{tabular}{|l|c|c|}
\hline \multicolumn{3}{|l|}{ Desire to Use } \\
\hline Variable & Coefficient & t-Stat \\
\hline Intercept & -0.476 & -1.315 \\
\hline Age & -0.013 & -0.873 \\
\hline Year & 0.004 & 0.071 \\
\hline Gender & 0.279 & $2.930^{*}$ \\
\hline NumMobileDev & 0.263 & $3.837 * *$ \\
\hline Adj. $\mathrm{R}^{2}$-Square & .039 & \\
\hline $\mathrm{N}$ & 541 & \\
\hline * significant at $5 \%$ level, & ** Significant at $1 \%$ level \\
\hline
\end{tabular}

Tables 1 through 4 present the results of the hypothesis $\mathrm{H} 1-\mathrm{H} 4$ respectively. Technically, all four null hypotheses can be rejected. However, one might argue that the rejection of $\mathrm{H} 4$ is not particularly enlightening as the students' desire to use mobile devices in class is very poorly explained by the available data. Further discussion of these results can be found in the next section. 


\title{
DISCUSSION \& CONCLUSIONS
}

\begin{abstract}
Research Questions
Pertaining to Research Question 1Ra, our results show that students already have access to the mobile technology necessary to make a formal BYOD policy a success (See Figures 2, 3, 4). In fact, zero students have no mobile device and the average student has 2.35 mobile devices. In addition, the students indicate that they plan to either upgrade their current devices or to purchase more devices at a rapid rate in the future. As a result, the implementation of a formal BYOD should not cause an undue financial hardship on the students.
\end{abstract}

Research Question R1b examines the reasons why students do not currently bring their mobile devices to the classroom. The primary reasons that students choose not bring their devices to class such as the perceptions that they are not allowed, not required, that they can't get an internet connection and the possibility of theft all have simple easy to implement solutions and can be mitigated with careful planning upfront during the creation of an official BYOD policy. (See Figures 5, 6, 7)

When examining the data for Research Question R2, it becomes clear that students already understand the legitimate academic benefits of using mobile technology in the classroom, and clearly want to use the technology more in the future. (See Figure 8).

\section{Hypotheses}

H4 is the hypothesis with the weakest empirical support. While the null hypothesis is rejected, the resulting equation does little to explain student Desires to use mobile devices in class. Whatever the determinants of a student's desire to use mobile devices in class, that desire contributes to their perceived benefits and ultimately their engagement.

The rejection of hypothesis $\mathbf{H 3}$ shows that the Desire to use more mobile technology leads to an increased perception of there being instructional Benefits of that technology. Unfortunately, student perceptions of Instructor attitudes have a negative impact on their perception of Benefits from using mobile technology in the classroom.

H2 can also be rejected indicating that the Benefits that students perceive by using mobile technology in the classroom have a positive impact on their Engagement in school while their perception of their Instructor's attitudes have a negative effect on their Engagement.

Finally, we can reject H1: the Benefits of the use of mobile technology, the student's Desire to use the technology, the potential for future Academic Preparation, and Instructor attitudes have a significant influence on student engagement. Unfortunately, once again, the Instructor's attitudes have a negative impact on student engagement.

With all four null hypotheses rejected, there is evidence supportive of the causal linkages posited in Figure 1. Student Desires to use mobile devices in the classroom and their perceived Academic Preparation have a positive impact on their Perceived Benefits from using mobile devices in class. Students who perceive more benefits to using mobile devices in the classroom would be more Engaged students. Students clearly believe that Academic Preparation, Perceived Benefits, and increased Engagement all follow from the increased usage of mobile computing devices in the classroom. The main obstacle that students see in the path toward using mobile technology in the classroom is their perceptions of their Instructors. In the eyes of the students the inability and/or unwillingness of Instructors to actively engage them in the classroom with the effective use of mobile technology poses a significant challenge. This finding seems to indicate that an educational BYOD policy cannot be successful without both the active engagement of the faculty in the creation of the policy and the training required so that the Faculty can effectively implement the use of mobile technology in the classroom.

\section{REFERENCES}

1. Brand, J., Kinash, S., Mathew, T., \& Kordyban, R. (2011). iWant does not equal iWill: Correlates of mobile learning with iPads, e-textbooks, BlackBoard Mobile Learn and a blended learning experience. Ascilite 2011, 1, 168-178. 


\section{Issues in Information Systems \\ Volume 15, Issue $x$, pp., 2014}

2. Clark, W., \& Luckin, R. (2013). Ipads in the Classroom. London Knowledge Lab,1, 1-31. Retrieved December 7, 2013, from http://www.thepdfportal.com/ipads-in-the-classroom-report-lk1_61713.pdf

3. Mayer, R., Still, A., DeLeeuw, K., Almeroth, K., Bimber, B., Chun, D., et al. (2009). Clickers in college classrooms: Fostering learning with questioning methods in large lecture classes.Contemporary Educational Psycology,34(1), 51-57. Retrieved December 9, 2013, from http://www.sciencedirect.com/science/article/

4. Murray, O., \& Olcese, N. (2011). Teaching and Learning with iPads, Ready or Not? TechTrends, 55(6), 42-48.

5. Pillay, A,. Nahm, E., Tan, G., Diaki, H., Senanayake, S., \& Deshpande, S. Does BYOD increase risks or drive benefits?

6. Rossing, J., Miller, W., Cecil, A., \& Stamper, S. (2012). iLearning: The future of higher education? Student perceptions on learning with mobile tablets. Scholarship of Teaching and Learning, 12(2), 1-26.

7. Sheehan, M., \& Caruso, J. (2011). Students and information technology in higher education: 2011--Survey questionnaire. Retrieved November 2013, from http://https://net.educause.edu/ir/library/pdf/SI/ESI11B.pdf

8. Smith, M., \& Kukulska-Hulme, A. (2012). Building Mobile Learning Capacity in Higher Education: E-books and iPads. In: Specht, Marcus; Multisilta, Jari and Sharples, Mike eds. 11th World Conference on Mobile and Contextual Learning. Helsinki: CELSTEC \& CICERO Learning, pp. 298-301. 